\title{
Distributed Secondary Voltage Regulation for Autonomous Microgrid
}

\author{
Mahmuda Begum, Mohammad Abuhilaleh, Li Li and Jianguo Zhu \\ Faculty of Engineering and Information Technology, University of Technology Sydney, Australia \\ Email: Mahmuda.Begum@student.uts.edu.au
}

\begin{abstract}
This research addresses the control problem of microgrids and presents a robust distributed secondary control system for voltage regulation of an islanded microgrid with droop-controlled and inverter-based distributed generators (DGs). A consensus-based distributed control approach is proposed to restore the voltage and frequency of the islanded microgrid to the reference values for all DGs within a very short time. The proposed method is flexible to system topology variations which aids the plugand-play operation of microgrid. An autonomous micogrid test system consisting of four DGs is constructed in MATLAB using SimPowerSystem Toolbox to test the proposed design method, and the simulation results show the effectiveness of the proposed control strategy. The performance of the proposed controller is shown through several test case studies.
\end{abstract}

Key Words-Hierarchical Control of Microgrid, Secondary Control, Consensus Control, Voltage Restoration.

\section{INTRODUCTION}

Microgrids can be defined as small-scale power distribution system to ease the integration of distributed generation (DG) units [1]. However, high penetration of renewable resources with their power electronics interfaces has raised challenges to operations and stability of power systems due to their nonlinear and intermittent characteristics as well as it leads to a change of conventional power system structure [2, 3]. Thus appropriate microgrid architectures and corresponding control methods are the key elements for regulating distributed energy resources (DERs) in order to maintain stability and protection of power systems. These prerequisites lead a hierarchical control structure [4-7] that eases the complicated control design of microgrid and addresses each constraint at a different control hierarchy.

The hierarchical control structure of microgrid consists of primary, secondary, and tertiary control levels. The main goal of primary control is to ensure the accurate power sharing among the DERs whereas the secondary control compensates the voltage and frequency deviations caused by the functioning of the primary control. The tertiary control deals with the power flow between the microgrid and the main grid, and concerns about the optimization of the microgrid based on efficiency and economics.

Coordination of the DERs for the active and reactive power sharing and the control of system voltage and frequency are the major challenges for autonomous microgrids $[3,8]$. The idea of conventional frequency and voltage droop control for microgrids has already been familiarized in the previous research work [5, 9-11]. Though the droop control technique $[5,9]$ can ensure the stability of a microgrid operation, the voltages and frequencies of the microgrid can still deviate from their nominal values. Therefore, applying a further control level, named as the secondary control can restore the microgrid frequency and voltage magnitudes to the reference level that deviates by the droop control in the primary control level. Numerous researches [8, 12-17] have mentioned the secondary control of islanded microgrids. Current secondary control methods comprise of centralized [18-20] and distributed configurations [14, $16,17,21]$.

A microgid central controller eliminates the frequency and voltage deviations caused by the local droop controllers in the conventional secondary control system [22]. The distributed secondary control system uses local neighboring rather than global data. The distributed secondary control has the benefits of enhanced system reliability, reduced sensitivity to failure, and removed necessity for a central complex computing and communication element. This offers a robust secondary control structure that works appropriately regardless of time varying, limited, and unreliable communication systems. In this paper, a distributed control strategy based on consensus control protocol is proposed in the secondary control layer for droop based primary controlled autonomous microgrid.

The main contributions of this paper are:

$>$ Voltage and frequency regulations are achieved by the proposed control method irrespective of system parameter changes, and the plug-and-play capability is also verified by this controlling method.

$>$ Reactive power sharing is also maintained by the proposed control method that is another major limitation of current control techniques.

$>$ Active power sharing can also be achieved accurately by the proposed control techniques while restoring the frequencies to their nominal values.

Moreover, according to the proposed control method, the dynamic performance is also improved with a faster and improved response. 


\section{Microgrid CONTROL STRUCTURE OVERVIEW}

In this paper, we study the primary and secondary control as tertiary control is not part of this paper.

\section{A. Primary Control}

The primary control level is the lower level control of hierarchical control structure, and it involves with the fastest dynamics of the network [9, 11, 23]. Generally, it has a decentralized architecture and information is locally measured at each distributed generation.

Droop control is extensively used in the primary control level of inverter-based microgrids [9, 22]. Droop technique offers a relation between the active power and the frequency and a relation between the reactive power and the voltage magnitude. For proper control of power sharing among the parallel-connected power electronics converters, there is no need of any communication link among them. Although, droop method retains some inherent benefits like no required communication, suitable for isolated system, offering flexibility, it undergoes from many adverse consequences discussed in [9], [10], [14], and [24], which limit its application. So, to overcome those limitations, several modified and advanced droop techniques are developed [23]. The primary droop control cannot avoid voltage and frequency deviations from reference values even with the modified droop techniques, which is the main problem for the autonomous microgrid.

In autonomous or islanded mode, Voltage Source Inverters (VSIs) are the main controllable interfaces with two main controlling phases [11]: 1) DG power sharing controller (for correcting real $(\mathrm{P})$ and reactive $(\mathrm{Q})$ power mismatches); and, 2) Inverter output controller (output voltage, current control). Practically, a VSI-based DG unit consists of a dc/ac inverter bridge, a prime dc power source, an inductor-capacitor (LC) filter and a resistorinductor (RL) output linking [24], as depicted in Fig. 1. The three control loops, namely current loop, voltage loop and power control loop, are found in the primary droop control. As studied in [25], the dynamics of the voltage and current control loops are much faster than those of the power control loop. Hence, neglecting these fast-dynamics blocks, we consider the primary controller for modelling.

In this paper, a basic microgrid comprising of $4 \mathrm{DG}$ units is considered. Each DG unit is linked to the respective load and interconnected with neighboring DG units through transmission lines. Coordination of the primary controllers can be achieved by considering the droop control for the real and reactive power. The following equation represents the droop controller of the $i^{\text {th }} \mathrm{DG}$ :

$$
f_{i}=f_{\text {ref }}-n_{f} P_{i}
$$$$
v_{i}=v_{\text {ref }}-n_{v} Q_{i}
$$

where $P_{i}$ is the real power and $Q_{i}$ is the reactive power of the $i^{\text {th }}$ DG units, $n_{f}$ is the frequency droop gain, $n_{v}$ is the voltage droop gain, $v_{r e f}$ is the nominal voltage, and $f_{\text {ref }}$ is the nominal frequency.

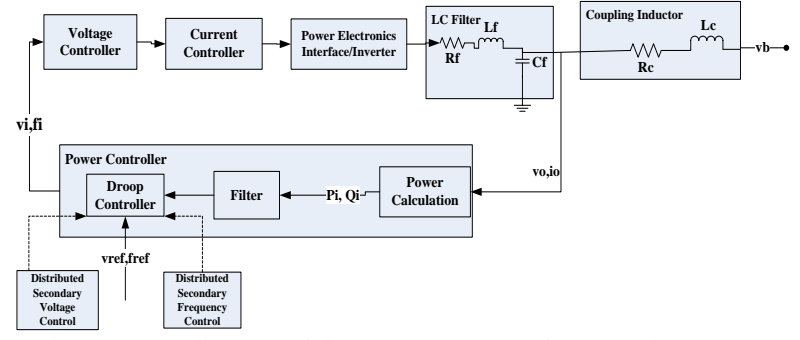

Fig. 1. Block diagram of the control system of a DG unit

\section{B. Secondary Control}

It has been mentioned that the objective of secondary control is to remove the steady-state deviations both in the global frequency and the local voltage arising from the proportion droop. To address the frequency and voltage restoration in islanded MGs, significant researches have already been carried out. Conventionally, secondary control is employed in the centralized control scheme, represented as microgrid central control (MGCC), which needs a complex communication network and may suffer from a single point-of-failure and massive amounts of data supervision [26] compared to the distributed control.

Distributed control scheme observes interaction among the units, assigning control responsibility to various units depending on action in several time frame [27]. Some recent studies based on distributed control scheme are briefly introduced here. A multi-agent system (MAS)based distributed cooperative technique has recently attracted the concern owing to its reliable structure using a sparse communication network where each DG unit only shares information with its immediate neighbors, and specific attribute of agents such as independence, proactivity, and flexibility. MAS-based techniques can be combination of MAS with cooperative control [14, 28-30] or distributed cooperative control [15]. Distributed model predictive control is proposed in $[17,31]$ where reactive power sharing is still the open research questions. In [13], feedback linearization method is proposed for distributed secondary control design. In [32], averaging PI control is proposed which ignores the synchronization requirement for voltage and frequency restoration of DG units. Finite time control is introduced in [21,33] where voltage restoration is still model-dependent with a severe oscillation in active power response when an additional load is connected to or disconnected from the MG.

Consensus control theories have recently attracted much more concentration due to their distributed nature [16, 34-36]. In particular, the consensus-based $P$ - $f$ droop control was first suggested in [37] while the consensusbased secondary control was proposed and established in [13]. In both methods, reactive power sharing and convergence rate problem remains for further research. To overcome the above mentioned limitations, a distributed control strategy based on consensus control theory is proposed in the secondary control layer. 


\section{CONSENSUS BASED DistRIBUTED SECONDARY CONTROL}

\section{A. Consensus Control Basics}

Consensus problem is one of the most basic and challenging problems in cooperative control. It is assumed that there are multiple agents on a network. This network is generally modeled by a graph connection of nodes (representing the agents) and edges (representing the interactions between agents). If all the agents on a network converge to a common state, the multi-agent system resolves a consensus problem or has a consensus property, and the common state is entitled group decision value or consensus state.

\section{B. Graph Theory}

A directed graph (diagraph) $\mathrm{G}=\left(N_{G}, E_{G}\right)$ with a set of $\mathrm{N}$ nodes, $N_{G}=\{1,2,3, \ldots \ldots, N\}$, a set of edges $E_{G} \subset$ $N_{G} \times N_{G}$ and an adjacency matrix $A_{G}=\left(a_{i j} \geq 0\right) \in$ $R^{N \times N}$ (where $a_{i j}=1$ if the $i^{\text {th }}$ node is connected to the $j^{\text {th }}$ node and otherwise $\left.a_{i j}=0\right)$ is introduced here. Each node denotes an agent, each edge $(i, j)$ (pointing from $j$ to $i$ ) denotes that data can flow from $j$ to $i$ with $a_{i j}$. Define the neighbors of node $i$ as $N_{i}=\left\{j \in N:(i, j) \in E_{G}\right\}$. Thus under this description, an agent/node $i$ only has access to information from his neighbors in $N_{i}$.

Let each agent (node) be a single-state system described by $\dot{x}_{\mathrm{i}}=u_{i}$ where $u_{i}$ is the input as a function of the $i^{\text {th }}$ agent's neighboring state $x_{j}, j \in N_{i}$. The usual practice is to take on the following consensus protocol: $\dot{x}_{\imath}=u_{i}=\sum_{j \in N_{i}} a_{i j}\left(x_{j}-x_{i}\right)$

\section{Consensus based Secondary Control for Voltage} Restoration

Thus the secondary control is achieved by choosing the proper control input $u_{i}$ to adjust the individual frequency $f_{i}$ and voltage magnitude $v_{i}$ to the respective references fref and vref synchronously, with all the agents acting as a group. Therefore, the consensus based secondary control for the $i^{\text {th }} \mathrm{DG}$ for voltage restoration can be written as

$$
\Delta \dot{v_{l}}=\left[\sum_{j \in N_{i}}\left(\Delta v_{j}-\Delta v_{i}\right)+g_{i}\left(\Delta v-\Delta v_{i}\right)\right]
$$

where $\Delta v_{i}$ is the secondary controller output and $\Delta v$ is the control signal calculated at the point of common coupling (PCC) through the following equation $\Delta v=k_{p}\left(v_{r e f}-v_{P C C}\right)+k_{I} \int\left(v_{r e f}-v_{P C C}\right) d t$

Here, $g_{i}=1$ if the $i^{t h}$ DG has direct communication with the controller at PCC and otherwise $g_{i}=0$. Combining the secondary control signal in (3) with the primary control signal in (1), the inverter voltage reference is shown below,

$$
v_{\text {refi }}=v_{i}+\Delta v_{i}
$$

\section{Simulation AND Results}

To test the effectiveness of the proposed secondary controller methodology, an autonomous MG shown in Fig. 2 . is constructed. The model consists of four DG units with the individual loads and transmission lines and is simulated in MATLAB using SimPowerSystems toolbox. The parameters for the MG model and control system are listed in Table 1. We assume that DG units communicate with neighbors through the directed graph (Fig. 2). For both the frequency and voltage restoration problems, we consider the voltage and frequency references to be the DG2 unit outputs. The whole simulation can be divided into 3 cases (Case 1, Case 2 and Case 3) in order to compare the effectiveness of the proposed secondary controller.

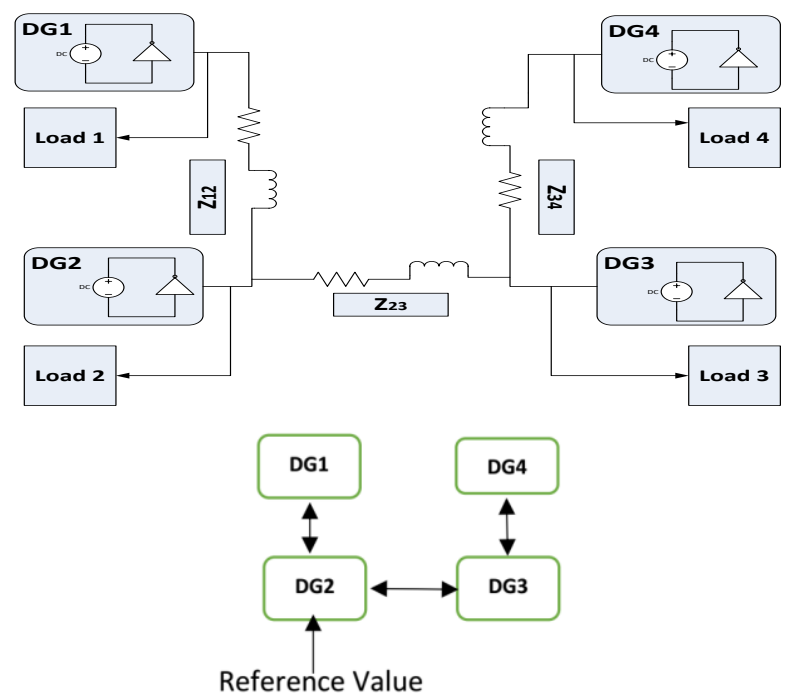

Fig. 2. Simulation diagram of the microgrid test model and the communication diagraph

Table 1: Parameters for the Inverters used in the Microgrid Test Model

\begin{tabular}{|c|c|c|c|}
\hline Description & Parameter & Value & Unit \\
\hline \multicolumn{4}{|c|}{ Microgrid Model Parameters } \\
\hline DC Voltage Value & $V_{d c}$ & 700 & $\mathrm{~V}$ \\
\hline Reference Voltage & $v_{\text {ref }}$ & 311 & $\mathrm{~V}$ \\
\hline Reference Frequency & $f_{\text {ref }}$ & 50 & $\mathrm{~Hz}$ \\
\hline $\begin{array}{l}\text { Resistance of Filter } \\
\text { Inductor }\end{array}$ & $R_{f}$ & 0.1 & $\Omega$ \\
\hline $\begin{array}{l}\text { Inductance of Filter } \\
\text { Inductor } \\
\end{array}$ & $L_{f}$ & 1.35 & $\mathrm{mH}$ \\
\hline $\begin{array}{l}\text { Capacitance of Filter } \\
\text { Inductor }\end{array}$ & $C_{f}$ & 50 & $\mu \mathrm{F}$ \\
\hline $\begin{array}{l}\text { Resistance of Coupling } \\
\text { Inductor }\end{array}$ & $R_{c}$ & 0.03 & $\Omega$ \\
\hline $\begin{array}{c}\text { Inductance of } \\
\text { Coupling Inductor }\end{array}$ & $L_{C}$ & 0.35 & $\mathrm{mH}$ \\
\hline \multicolumn{4}{|c|}{ Voltage Controller Parameters } \\
\hline Proportional Gain & $K_{p v}$ & 0.05 & \\
\hline Integral Gain & $K_{i v}$ & 390 & \\
\hline Feed Forward Gain & $\mathrm{F}$ & 0.75 & \\
\hline \multicolumn{4}{|c|}{ Current Controller Parameters } \\
\hline Proportional Gain & $K_{p c}$ & 10.2 & \\
\hline Integral Gain & $K_{i c}$ & $16 \mathrm{e} 3$ & \\
\hline
\end{tabular}
System 
Table 2: Load and Line Data used in the Microgrid Test Model System

\begin{tabular}{|c|c|c|}
\hline Line Data & $\begin{array}{c}\text { Line Resistance } \\
(\Omega)\end{array}$ & $\begin{array}{c}\text { Line Inductance } \\
(\mu \mathrm{H})\end{array}$ \\
\hline Line $1, Z_{12}$ & 0.23 & 318 \\
\hline Line $2, Z_{23}$ & 0.23 & 318 \\
\hline Line $3, Z_{34}$ & 0.30 & 312 \\
\hline
\end{tabular}

\begin{tabular}{|c|c|c|}
\hline Load Data & $\begin{array}{c}\text { Load } \\
\text { Resistance, } \mathrm{R}(\Omega)\end{array}$ & $\begin{array}{c}\text { Load Inductance, L } \\
(\mathrm{mH})\end{array}$ \\
\hline Load\# 1 & 50 & 35 \\
\hline Load \# 2 & 50 & 35 \\
\hline Load \# 3 & 35 & 35 \\
\hline Load \# 4 & 35 & 35 \\
\hline Load \# 5 & 25 & 25 \\
\hline
\end{tabular}

Table 3: Parameters of the Power Controller used in the Microgrid Test Model System

\begin{tabular}{|c|c|c|c|c|}
\hline $\begin{array}{c}\text { DG } \\
\text { unit }\end{array}$ & $\begin{array}{c}\text { Active Power } \\
\text { rating (KW) }\end{array}$ & $\begin{array}{c}\text { Reactive } \\
\text { Power Rating } \\
\text { (KVar) }\end{array}$ & $\begin{array}{c}\text { Frequency } \\
\text { Droop } \\
\text { Gain, } n_{f}\end{array}$ & $\begin{array}{c}\text { Voltage } \\
\text { Droop } \\
\text { Gain, } n_{v}\end{array}$ \\
\hline DG1 & 60 & 30 & $3.33 \mathrm{e}-5$ & $1.67 \mathrm{e}-5$ \\
\hline DG2 & 60 & 30 & $3.33 \mathrm{e}-5$ & $1.67 \mathrm{e}-4$ \\
\hline DG3 & 30 & 15 & $6.67 \mathrm{e}-5$ & $3.33 \mathrm{e}-4$ \\
\hline DG4 & 30 & 15 & $6.67 \mathrm{e}-5$ & $3.33 \mathrm{e}-4$ \\
\hline
\end{tabular}

The three cases are:

Case 1: Only primary control is activated.

Case 2: In this case, conventional secondary control is applied with the primary control.

Case 3: In this case, the proposed secondary control is activated from the beginning in combination with primary control.

For all the cases, five scenarios are analyzed in the simulation according to the power flow and the loading condition at each distributed generations as follows:

1) At $t=2 s$, Load \#3 is connected.

2) At $t=4 s$, Load \#2 is increased by including an additional load,Load\#5.

3) At $\mathrm{t}=6 \mathrm{~s}$, Load \#5 is disconnected from DG2.

4) At $t=8 s$, DG\# 4 is disconnected.

5) At $t=10 s$, DG\#4 is again connected.

The simulation results for Case 1, Case 2 and Case 3 are shown in Fig. 3, Fig. 4 and Fig. 5, respectively.

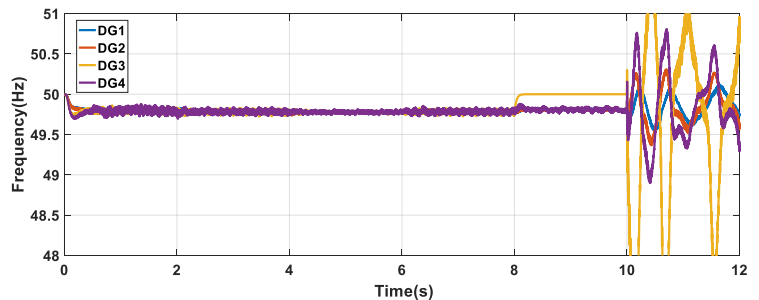

(a)

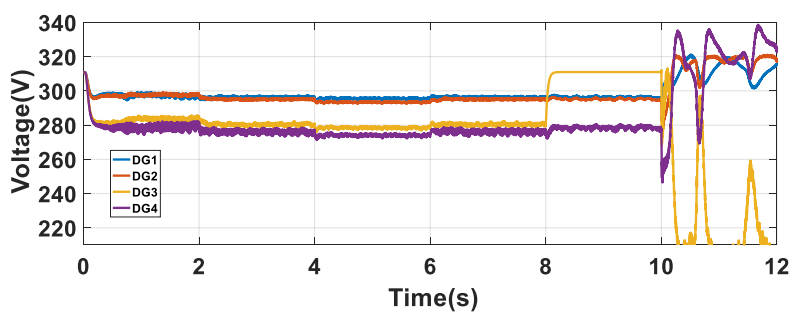

(b)

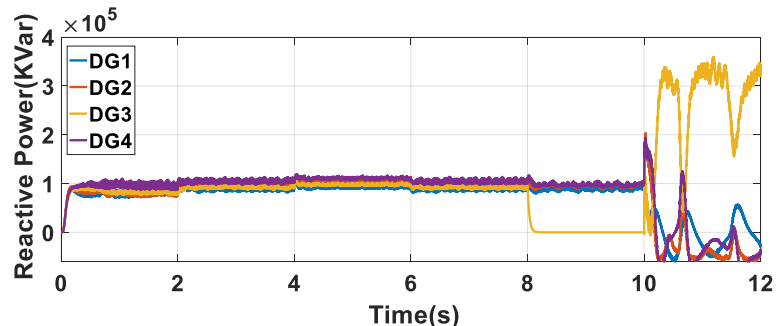

(c)

Fig. 3. Outputs of 4 DGs for Case 1, (a) frequency (b) voltage and (c) reactive Power

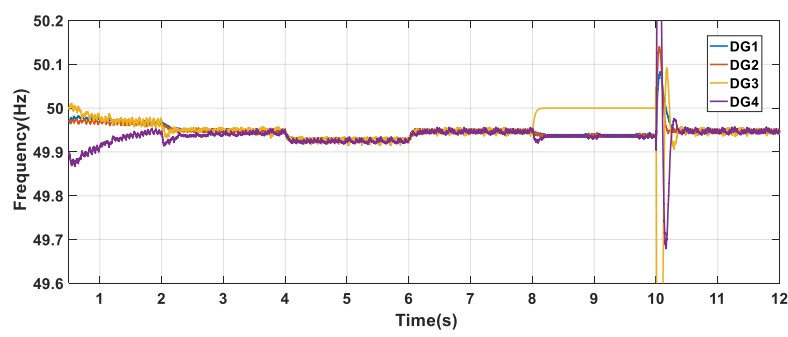

(a)

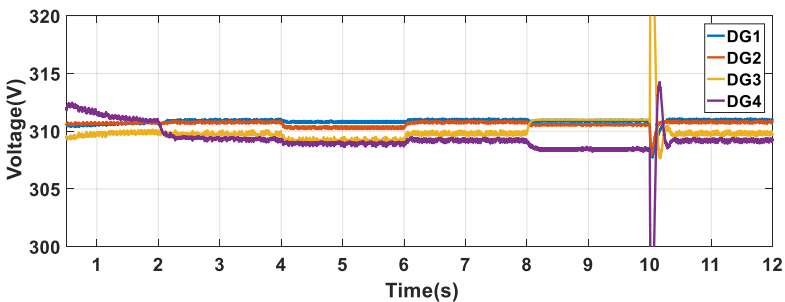

(b)

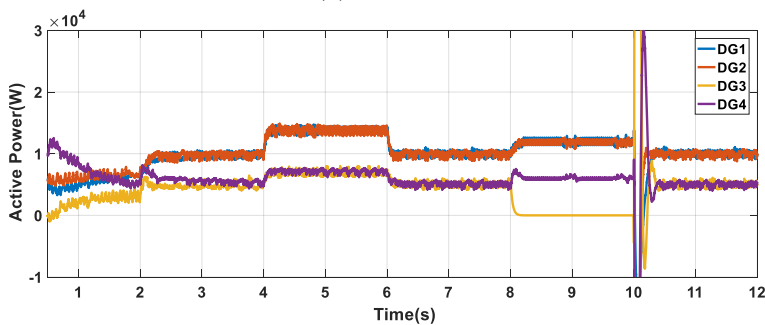

(c)

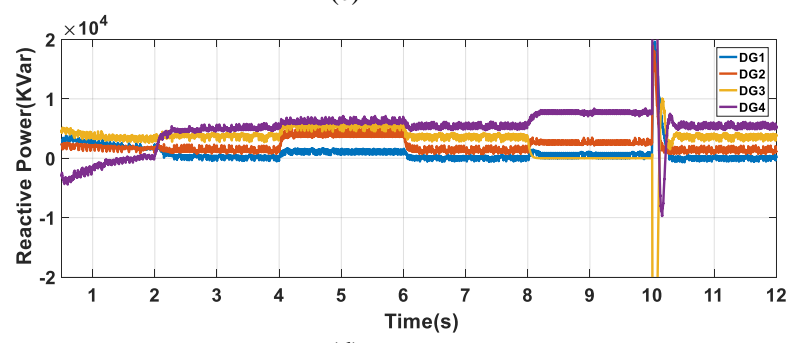

(d)

Fig. 4. Outputs of 4 DGs for Case 2, (a) frequency (b) voltage and (c) active power and (d) reactive power

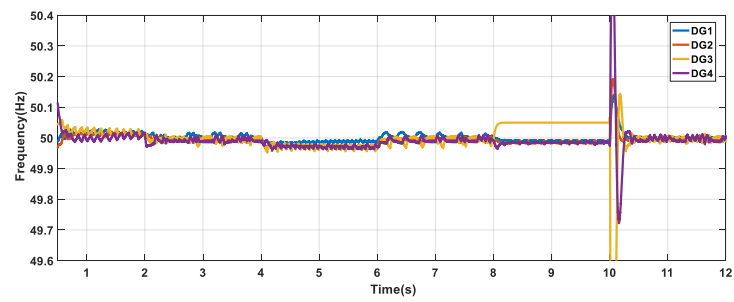

(a) 


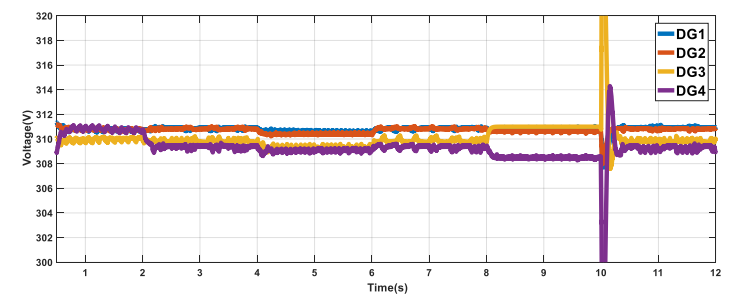

(b)

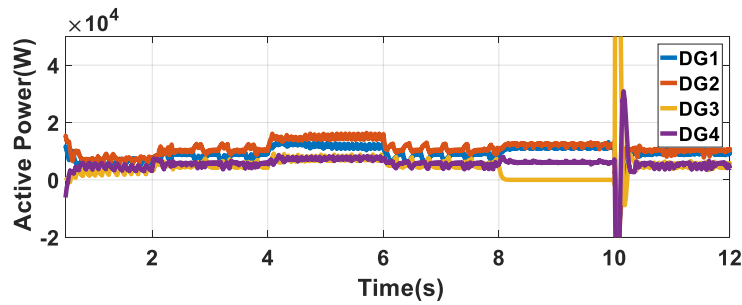

(c)

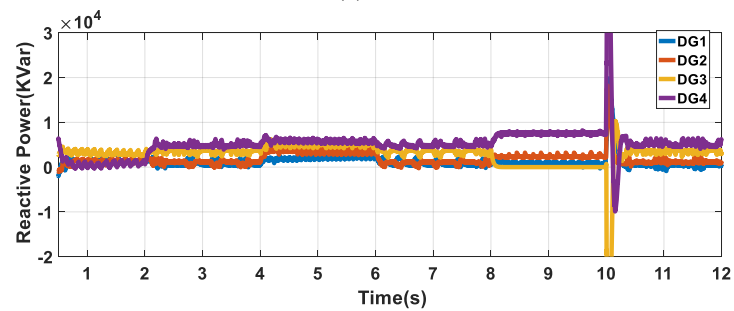

(d)

Fig. 5. Outputs of 4 DGs for Case 3, (a) frequency (b) voltages (c) active power and $(\mathrm{d})$ reactive power

As seen from Fig. 3, due to the droop function in the primary control, the voltage amplitudes of 4 DGs fall down to different values $(\mathrm{DG} 1=298 \mathrm{~V}, \mathrm{DG} 2=296 \mathrm{~V}, \mathrm{DG} 3=280 \mathrm{~V}$ and DG4 $=282 \mathrm{~V}$ ) while the frequency can synchronize to a common value $(49.76 \mathrm{~Hz})$. From the simulation results, it is clear that both voltage and frequency deviate from their reference values; hence, they need to be restored to their reference values in the secondary control layer.

When the conventional central control technique is applied in the secondary layer (Case 2), the voltage and frequency can be restored to their reference values but their responses are slower than that of our proposed distributed control; see Fig. 4. When our proposed distributed secondary control is applied (Case 3), both voltage and frequency can be quickly restored to their reference values respectively $\left(v_{\text {ref }} \approx 311 \mathrm{~V}, \mathbf{f}_{\text {ref }} \approx \mathbf{5 0 H z}\right.$ ), which is shown in Fig. 5. The steady state frequencies of the four DGs remain at reference value $(\mathbf{\approx 5 0} \mathbf{H z})$ no matter any load is connected to DG2 and DG4 or any load is disconnected from DG2. Moreover, in Case 3, the performance of plugand-play (scenarios 4\&5) capability shows the better results compared with the performance in Case 2 and Case 1.This result shows that the designed distributed secondary controller can eliminate the voltage and frequency deviation caused by the primary control.

The real power outputs of the four DGs are also tested (Fig. 4 and Fig. 5). Before the secondary control is activated (for Case 1), the real power sharing is well achieved by the primary control, i.e., P1 : P2 : P3 : P4 = $1 / \mathrm{n}_{\mathrm{f} 1}: 1 / \mathrm{n}_{\mathrm{f} 2}: 1 / \mathrm{n}_{\mathrm{f} 3}: 1 / \mathrm{n}_{\mathrm{f} 4}=2: 2: 1: 1$. When the secondary control is started (for Case 2 ), real powers are still well shared according to the designed droop grains regardless of load increasing or decreasing. Reactive power sharing is also good enough for the proposed distributed secondary controller while it is difficult for primary droop control techniques (Fig. 3 and Fig. 4).

As mentioned in the introduction, there are limited approaches to solve voltage and frequency restoration problems in a distributed way. However, we just made the comparison between the conventional method in both primary and secondary level (Case 1 and Case 2) and our proposed method. Another thing is that, the settling time for our proposed method is $0.5 \mathrm{~s}$ compared to some similar studies where the settling times are $1.5 \mathrm{~s}-2.5 \mathrm{~s}$ [15]. Thus, it is clear from the simulation results that our proposed method also ensures the fast convergence.

\section{CONCLUSION AND FUTURE WORK}

This result shows that the designed distributed secondary controller can remove the voltage and frequency deviation caused by the primary control. The simulation results show that the proposed controller can also keep a good real power and reactive power sharing accuracy under the load disturbances and plug-and-play operation. Experimental analysis for the proposed model will be done in our extended work. A satisfactory local stability condition with the detailed stability analysis for proposed microgrid model will also be given in our future work.

\section{REFERENCES}

[1] X. S. Zhou, L. Y. Yin, and Y. J. Ma, "An Overview of MicroGrid," Applied Mechanics and Materials, vol. 552, pp. 99102, Jun 2014 2016-01-15 2014.

[2] Q. Fu, A. Nasiri, A. Solanki, A. Bani-Ahmed, L. Weber, and V. Bhavaraju, "Microgrids: Architectures, Controls, Protection, and Demonstration," Electric Power Components and Systems, vol. 43, p. 1453, 2015 2015-09-23 2015.

[3] A. Kumar and M. L. Azad, "CHALLENGES IN RECENT MICROGRID SYSTEMS: A REVIEW," International Journal of Advances in Engineering \& Technology, vol. 8, pp. 203-210, Apr 2015 2015-05-23 2015.

[4] A. Bidram and A. Davoudi, "Hierarchical Structure of Microgrids Control System," IEEE Transactions on Smart Grid, vol. 3, pp. 1963-1976, 2012.

[5] J. M. Guerrero, J. C. Vasquez, J. Matas, L. G. de Vicuna, and M. Castilla, "Hierarchical Control of Droop-Controlled AC and DC Microgrids\&\#x2014;A General Approach Toward Standardization," IEEE Transactions on Industrial Electronics, vol. 58, pp. 158-172, 2011.

[6] Y. Han, H. Li, P. Shen, E. A. A. Coelho, and J. M. Guerrero, "Review of Active and Reactive Power Sharing Strategies in Hierarchical Controlled Microgrids," IEEE Transactions on Power Electronics, vol. 32, pp. 2427-2451, 2017.

[7] E. Planas, A. Gil-de-Muro, J. Andreu, I. Kortabarria, and I. Martínez de Alegría, "General aspects, hierarchical controls and droop methods in microgrids: A review," Renewable and Sustainable Energy Reviews, vol. 17, pp. 147-159, 1// 2013.

[8] A. Bidram, "Distributed cooperative control of AC microgrids," 3639639 Ph.D., The University of Texas at Arlington, Ann Arbor, 2014 
[9] Z. Ahmad and S. N. Singh, "DROOP Control Strategies of Conventional Power System Versus Microgrid Based Power Systems - A Review," pp. 1499-1504, 2015.

[10] D. Petreus, R. Etz, T. Patarau, and C. Orian, "MICROGRID CONCEPT BASED ON DISTRIBUTED RENEWABLE GENERATORS FOR A GREENHOUSE," Acta Technica Napocensis, vol. 56, pp. 31-36, 2015 2015-07-06 2015.

[11] Z. Shuai, S. Mo, J. Wang, Z. J. Shen, W. Tian, and Y. Feng, "Droop control method for load share and voltage regulation in high-voltage microgrids," Journal of Modern Power Systems and Clean Energy, vol. 4, pp. 76-86, 2016.

[12] C. Ahumada, R. Cardenas, D. Saez, and J. M. Guerrero, "Secondary Control Strategies for Frequency Restoration in Islanded Microgrids With Consideration of Communication Delays," IEEE Transactions on Smart Grid, vol. 7, pp. 1430$1441,2016$.

[13] A. Bidram, A. Davoudi, F. L. Lewis, and J. M. Guerrero, "Distributed Cooperative Secondary Control of Microgrids Using Feedback Linearization," IEEE Transactions on Power Systems, vol. 28, pp. 3462-3470, 2013.

[14] A. Bidram, F. L. Lewis, Z. Qu, and A. Davoudi, "Secondary control of microgrids based on distributed cooperative control of multi-agent systems," IET Generation, Transmission \& Distribution, vol. 7, pp. 822-831, 2013.

[15] N. M. Dehkordi, N. Sadati, and M. Hamzeh, "Fully Distributed Cooperative Secondary Frequency and Voltage Control of Islanded Microgrids," IEEE Transactions on Energy Conversion, vol. PP, pp. 1-1, 2016.

[16] F. Guo, C. Wen, J. Mao, and Y.-D. Song, "Distributed Secondary Voltage and Frequency Restoration Control of Droop-Controlled Inverter-Based Microgrids," IEEE Transactions on Industrial Electronics, vol. 62, pp. 43554364, 2015.

[17] G. Lou, W. Gu, Y. Xu, M. Cheng, and W. Liu, "Distributed MPC-Based Secondary Voltage Control Scheme for Autonomous Droop-Controlled Microgrids," IEEE Transactions on Sustainable Energy, vol. 8, pp. 792-804, 2017.

[18] C. Gang and G. Zhijun, "Distributed secondary control for droop-controlled autonomous microgrid," in 2015 34th Chinese Control Conference (CCC), 2015, pp. 9008-9013

[19] T. Dragičević and F. Blaabjerg, "Chapter 9 - Power Electronics for Microgrids: Concepts and Future Trends A2 - Mahmoud, Magdi S," in Microgrid, ed: ButterworthHeinemann, 2017, pp. 263-279.

[20] D. E. Olivares, C. A. Cañizares, and M. Kazerani, "A centralized optimal energy management system for microgrids," in 2011 IEEE Power and Energy Society General Meeting, 2011, pp. 1-6.

[21] N. Mahdian Dehkordi, N. Sadati, and M. Hamzeh, "Distributed Robust Finite-Time Secondary Voltage and Frequency Control of Islanded Microgrids," IEEE Transactions on Power Systems, pp. 1-1, 2016.

[22] M. Aminu and K. Solomon, "A Review of Control Strategies for Microgrids," Advances in Research, vol. 7, pp. $1-9,2016$.

[23] H. Han, X. Hou, J. Yang, J. Wu, M. Su, and J. M. Guerrero, "Review of Power Sharing Control Strategies for Islanding Operation of AC Microgrids," IEEE Transactions on Smart Grid, vol. 7, pp. 200-215, 2016.

[24] F. Guo, C. Wen, J. Mao, and Y. D. Song, "Distributed Secondary Voltage and Frequency Restoration Control of Droop-Controlled Inverter-Based Microgrids," IEEE Transactions on Industrial Electronics, vol. 62, pp. 43554364, 2015.

[25] N. Pogaku, M. Prodanovic, and T. C. Green, "Modeling, Analysis and Testing of Autonomous Operation of an
Inverter-Based Microgrid," IEEE Transactions on Power Electronics, vol. 22, pp. 613-625, 2007.

[26] A. Kaur, J. Kaushal, and P. Basak, "A review on microgrid central controller," Renewable and Sustainable Energy Reviews, vol. 55, pp. 338-345, 3// 2016.

[27] M. Yazdanian and A. Mehrizi-Sani, "Distributed Control Techniques in Microgrids," IEEE Transactions on Smart Grid, vol. 5, pp. 2901-2909, 2014.

[28] F. Chen, M. Chen, Q. Li, K. Meng, J. M. Guerrero, and D. Abbott, "Multiagent-Based Reactive Power Sharing and Control Model for Islanded Microgrids," IEEE Transactions on Sustainable Energy, vol. 7, pp. 1232-1244, 2016.

[29] A. Kantamneni, L. E. Brown, G. Parker, and W. W. Weaver, "Survey of multi-agent systems for microgrid control," Engineering Applications of Artificial Intelligence, vol. 45, pp. 192-203, 2015.

[30] L. Raju, R. S. Milton, and A. Amalraj Morais, "Autonomous Energy Management of a Micro-Grid using Multi Agent System," Indian Journal of Science and Technology, vol. 9, 2016.

[31] R. Halvgaard, L. Vandenberghe, N. K. Poulsen, H. Madsen, and J. B. Jorgensen, "Distributed Model Predictive Control for Smart Energy Systems," IEEE Transactions on Smart Grid, vol. 7, pp. 1675-1682, 2016.

[32] J. W. Simpson-Porco, Q. Shafiee, F. Dorfler, J. C. Vasquez, J. M. Guerrero, and F. Bullo, "Secondary Frequency and Voltage Control of Islanded Microgrids via Distributed Averaging," IEEE Transactions on Industrial Electronics, vol. 62, pp. 7025-7038, 2015.

[33] Y. Zhao, Z. Duan, G. Wen, and Y. Zhang, "Distributed finite-time tracking control for multi-agent systems: An observer-based approach," Systems \& Control Letters, vol. 62, pp. 22-28, 2013.

[34] N. M. Dehkordi, N. Sadati, and M. Hamzeh, "Fully Distributed Cooperative Secondary Frequency and Voltage Control of Islanded Microgrids," IEEE Transactions on Energy Conversion, vol. 32, pp. 675-685, 2017.

[35] R. Fu, Y. Wu, H. Wang, and J. Xie, "A Distributed Control Strategy for Frequency Regulation in Smart Grids Based on the Consensus Protocol," Energies, vol. 8, pp. 7930-7944, 2015.

[36] Q. Shafiee, T. Dragicevic, F. Andrade, J. C. Vasquez, and J. M. Guerrero, "Distributed consensus-based control of multiple DC-microgrids clusters," pp. 2056-2062, 2014.

[37] J. W. Simpson-Porco, F. Dörfler, and F. Bullo, "Synchronization and power sharing for droop-controlled inverters in islanded microgrids," Automatica, vol. 49, pp. 2603-2611, 2013/09/01/2013. 